\title{
Moxibustion for treating patients with post-stroke depression: a systematic review and meta-analysis
}

\author{
Shi-Qi Guo ${ }^{1}$, Guo-Zhen Zhao ${ }^{2,3}$, Si-Ting $\mathrm{Li}^{1} \wedge$, Qin $\mathrm{Yao}^{1}, \mathrm{Li} \mathrm{Han}^{4}$, Bo $\mathrm{Li}^{2,3}$, Hao Wang ${ }^{5}$, Ya-Jie Liu ${ }^{1}$, \\ Bai-Xiao Zhao ${ }^{6 \wedge}$ \\ ${ }^{1}$ School of Acupuncture-Moxibustion and Tuina, Beijing University of Chinese Medicine, Beijing, China; ${ }^{2}$ Evidence-Based Medicine Center, Beijing, \\ China; ${ }^{3}$ Beijing Hospital of Traditional Chinese Medicine, Capital Medical University, Beijing, China; ${ }^{4}$ School of Traditional Chinese Medicine, \\ Beijing University of Chinese Medicine, Beijing, China; ${ }^{5}$ Department of Acupuncture and Moxibustion, The Sixth Medical Center of PLA General \\ Hospital, Beijing, China; ${ }^{6}$ Department of Acupuncture-Moxibustion, Dongzhimen Hospital, Beijing University of Chinese Medicine, Beijing, China \\ Contributions: (I) Conception and design: SQ Guo, BX Zhao; (II) Administrative support: SQ Guo, BX Zhao; (III) Provision of study materials \\ or patients: SQ Guo, GZ Zhao, L Han, H Wang, YJ Liu; (IV) Collection and assembly of data: SQ Guo, GZ Zhao, ST Li; (V) Data analysis and \\ interpretation: SQ Guo, GZ Zhao, Q Yao, B Li, ST Li; (VI) Manuscript writing: All authors; (VII) Final approval of manuscript: All authors. \\ Correspondence to: Bai-Xiao Zhao. Department of Acupuncture-Moxibustion, Dongzhimen Hospital, Beijing University of Chinese Medicine, Beijing \\ 100700, China. Email: baixiao100@vip.sina.com.
}

Background: To assess the effectiveness and safety of moxibustion for post-stroke depression (PSD).

Methods: A search was conducted in the following English and Chinese databases: Medline, Embase, Cochrane Central Register of Controlled Trials (CENTRAL), China National Knowledge Infrastructure (CNKI), Chinese Biomedical Literature (CBM), VIP and Wanfang. The outcomes included Hamilton Depression Rating Scale (HAMD), effective rate, and Modified Edinburgh-Scandinavian Stroke Scale (MESSS) scale. The formulation of search strategy, data extraction, and quality evaluation of involved studies was performed according to Cochrane handbook guidelines. The software RevMan 5.4 and Stata 16 were used for data analysis. The evidence quality of each outcome was evaluated by GRADEpro guideline development tool (GDT).

Results: A total of 14 trials with 863 participants were included. A certain risk of bias of unclear or high was detected in the included studies. Compared with the control group, adding moxibustion could change the value of HAMD [standardized mean difference $(\mathrm{SMD})=-1.17 ; 95 \%$ confidence interval (CI): -1.55 to $-0.79 ; \mathrm{I}^{2}=85.5 \% ; \mathrm{P}<0.01$ ] and the effective rate [risk ratio $(\mathrm{RR})=1.22 ; 95 \% \mathrm{CI}: 1.13$ to $1.32 ; \mathrm{I}^{2}=0.0 \%$; $\mathrm{P}=0.56]$, and the differences in the MESSS scale (SMD $=-0.72 ; 95 \% \mathrm{CI}:-1.06$ to $-0.38 ; \mathrm{I}^{2}=0.0 \% ; \mathrm{P}=0.80$ ) had statistical differences. The certainty was low in effective rate, and very low in HAMD and MESSS. Besides, moxibustion was shown to be generally safe.

Discussion: This review found that moxibustion may be an effective intervention for PSD. However, the results of this study have a certain limitation. The benefits of moxibustion for PSD need to be confirmed in the future by more high-quality randomized controlled trials (RCTs).

Keywords: Moxibustion; post-stroke depression (PSD); efficacy; meta-analysis; effectiveness

Submitted Nov 02, 2021. Accepted for publication Dec 30, 2021.

doi: 10.21037/apm-21-3421

View this article at: https://dx.doi.org/10.21037/apm-21-3421

\footnotetext{
^ ORCID: Shi-Qi Guo, 0000-0002-3866-6022; Guo-Zhen Zhao, 0000-0001-5736-1323; Si-Ting Li, 0000-0003-1784-531X; Li Han, 00000002-4857-6610; Bo Li, 0000-0002-4857-6610; Bai-Xiao Zhao, 0000-0002-9948-8186.
} 


\section{Introduction}

Post-stroke depression (PSD) is a common and serious complication after stroke, with an estimated prevalence ranging from $25 \%$ to as high as $79 \%$ (1). Additionally, PSD is the main limiting factor of recovery and rehabilitation in stroke patients (2). The interaction between depression and stroke may play an important role in the development of PSD (3), and it has been seen that PSD can increase mortality by up to 10 times (4). It is determined by biological and psychosocial factors, symptoms of which can be categorized into three dimensions: affective, somatic, and cognitive $(5,6)$. Social activities and cognitive function are negatively affected by PSD, which is characterized by depression, dysphasia, functional impairment, living alone, and social isolation $(7,8)$. In addition, emotional injury, phlegm and blood stasis and Qi deficiency were the main causes leading to PSD, based on Chinese traditional medicine. Depression after stroking can increase morbidity, mortality, and worsened functional recovery $(9,10)$. Concurrently, additional stress can be caused by the burden of medical costs and social pressures. Thus, it is very important to treat PSD patients.

The are many methods of treating PSD, including both pharmacological and non-pharmacological therapies (11). However, antidepressant drugs can have serious side effects. For example, selective serotonin reuptake inhibitors (SSRIs) may cause bleeding and intracerebral hemorrhage (12). The tolerability of antidepressants by patients at a late stage of PSD is also a shortcoming of pharmacological therapies (13). Due to the prevalence of the neuropsychiatric disorder that is PSD, finding an effective, safe, and convenient method is necessary (14).

As a traditional Chinese external therapy, moxibustion involves burning mugwort, called ai-ye in China, to produce a warm effect on the meridians, acupoints, and surface areas of the body $(15,16)$. Moxibustion plays a key role in regulating the innate yin and yang in the body, therefore its application is very common in many disorders, such as knee osteoarthritis, irritable bowel syndrome, cancer-related fatigue, coronavirus disease 2019, and alleviating side effects of chemotherapy or radiotherapy in cancer patients (17-22). Nevertheless, as an important part of acupuncture, up to nowadays, moxibustion therapy has not been widely promoted worldwide.

The therapy of moxibustion includes moxa-stick moxibustion and moxa-cone moxibustion. Moxa-cone moxibustion includes direct moxibustion and indirect moxibustion. The materials of indirect moxibustion such as salt, ginger slice, garlic slice, and monkshood, can be placed between skin and moxa to produce a desired effect (23). The recognized effective moxibustion pathways can be divided into four aspects: warming effect, infrared radiation, medicinal penetration, and aromatherapy (24). Several studies have supported the anti-depression effect of moxibustion. Even more importantly, prolonged treatment of moxibustion could promote the brain uptake of L-tryptophan (Trp), shifting the Trp metabolism to 5-hydroxytryptamine (5-HT) (25-27).

There were two similar meta-analyses about the acupuncture and herbal medicine for treating patients with PSD. One evaluated the effectiveness and safety of Chinese herbal medicine (CHM) versus fluoxetine on depression. Although the results were weak evidence, the study showed CHM had similar effect to fluoxetine on depression (28). In addition, the other meta-analysis showed that acupuncture or moxibustion plus cognitive rehabilitation, versus cognitive rehabilitation; meanwhile, acupuncture versus antidepressant demonstrated statistically significantly alleviated depression in comparing to cognitive rehabilitation (29). In our review, subgroup analysis was performed on moxibustion alone and moxibustion combined with other therapies. We comprehensively evaluated the clinical efficacy of moxibustion on PSD.

Dozens of clinical studies relevant to moxibustion have been conducted, with results supporting that moxibustion is an effective alternative therapy for depression. Moxibustion has been applied widely in PSD treatment (30), and several clinical trials have shown that moxibustion is an effective method for treatment of PSD (31-44). However, there has no high-quality systematic review conducted to evaluate the efficacy and safety of moxibustion for PSD. Our research conducted a search for both Chinese and English literature. After screening, the remaining 14 articles were all in Chinese. We speculated the reason was that moxibustion therapy had not been popularized around the world, so the majority of clinical trials were conducted in China. In this systematic review, the aim was to provide some desirable propositions and assess whether it is an effective therapeutic supplement for patients with PSD. We present the following article in accordance with PRISMA reporting checklist (available at https://apm.amegroups.com/article/ view/10.21037/apm-21-3421/rc) (45).

\section{Methods}

The protocol has been registered on the PROSPERO 
platform (CRD42020178218).

\section{Data sources and search strategy}

The following English and Chinese databases were searched: Medline, Embase, Cochrane Central Register of Controlled Trials (CENTRAL), China National Knowledge Infrastructure (CNKI), Chinese Biomedical Literature (CBM), VIP, and Wanfang. The search was conducted independently by two reviewers on 15 August 2021. The search strategy was formulated according to the Cochrane handbook guidelines (46). The PubMed search strategy is shown in Table S1. The two authors independently conducted a preliminary screening based on the title and abstracts of the searched articles. If the studies met the inclusion criteria, they were re-screened based on the full text, to obtain the finally included studies. Excluded studies during re-screening had their exclusion explanations recorded. In addition, the references of the included studies were read to identify additional relevant studies.

\section{Inclusion criteria}

(I) Participants: patients with ischemic or hemorrhagic stroke and stroke mortality, whom were subsequently experiencing depression (47). (II) Interventions: all kinds of moxibustion therapies alone or those combined with conventional treatment were included. Moxibustion therapies included moxa-stick moxibustion, incorporating mild moxibustion, pecking moxibustion, cyclomoxibustion (in a circular motion), and moxa-cone moxibustion, which consisted of direct moxibustion and indirect moxibustion. (III) Comparisons: the patients were given conventional treatment, including fluoxetine, psychology, CHM, or acupuncture. (IV) Outcomes: the primary outcome was the score from the Hamilton Depression Rating Scale (HAMD), and secondary outcomes were the effective rate and the score from the Modified Edinburgh-Scandinavian Stroke Scale (MESSS). (V) Study types: randomized controlled trials (RCTs).

\section{Exclusion criteria}

(I) Moxa needle therapy was excluded, which consists of a needle inserted into a point with a moxa attached to and ignited at the handle of the needle. (II) Full text unavailable.

\section{Data extraction}

The data was extracted from each document by two reviewers independently. The information extracted included author name, published year, sample size, gender, age, interventions and control characteristics (e.g., specific intervention, frequency, duration), and outcomes (primary and secondary outcomes specifically mentioned above). Any disagreements between reviewers were resolved by consultation with a third reviewer.

\section{Quality assessment}

The risk of bias was assessed by two reviewers with the Cochrane Collaboration's tool for risk of bias assessment. The Cochrane risk of bias tool (ROB) by RevMan 5.4 (Computer program; The Cochrane Collaboration, Copenhagen, Denmark, 2020) was used to evaluate the quality of the included studies from seven aspects: random sequence generation, allocation concealment, blinding of participants and personnel, blinding of outcome assessors, incomplete outcome data, selective outcome reporting, and other sources of bias (48). Each aspect could be divided into three levels: low risk, high risk, and unclear risk.

\section{Data synthesis and Statistical analysis}

Data synthesis was carried out using the risk ratio (RR) and standardized mean difference (SMD) with 95\% confidence interval (CI) to analyze the outcomes. Heterogeneity analysis included of all kinds of variations among the trials.

Chi-square-based Q-test will be used to check heterogeneity. When $\mathrm{I}^{2} \leq 50 \%$, the study was not considered to have significant heterogeneity. When $\mathrm{I}^{2}>50 \%$, a possible significant heterogeneity was considered. Moreover, if there was no significant heterogeneity, the fixed-effects model was applied to data synthesis (49). Otherwise, the random-effects model was used for data synthesis. Any comparison with high heterogeneity will be explored by subgroup analyses or sensitivity analysis. In addition, the study design and characteristics in the included studies will be analyzed.

The funnel plot, Begg's test, and Egger's test were used to assess the publication bias if more than 10 RCTs were included for primary outcome. Statistical analysis was performed using the software Stata 16 (StataCorp., LLC, College Station, TX, USA) and RevMan 5.4. 


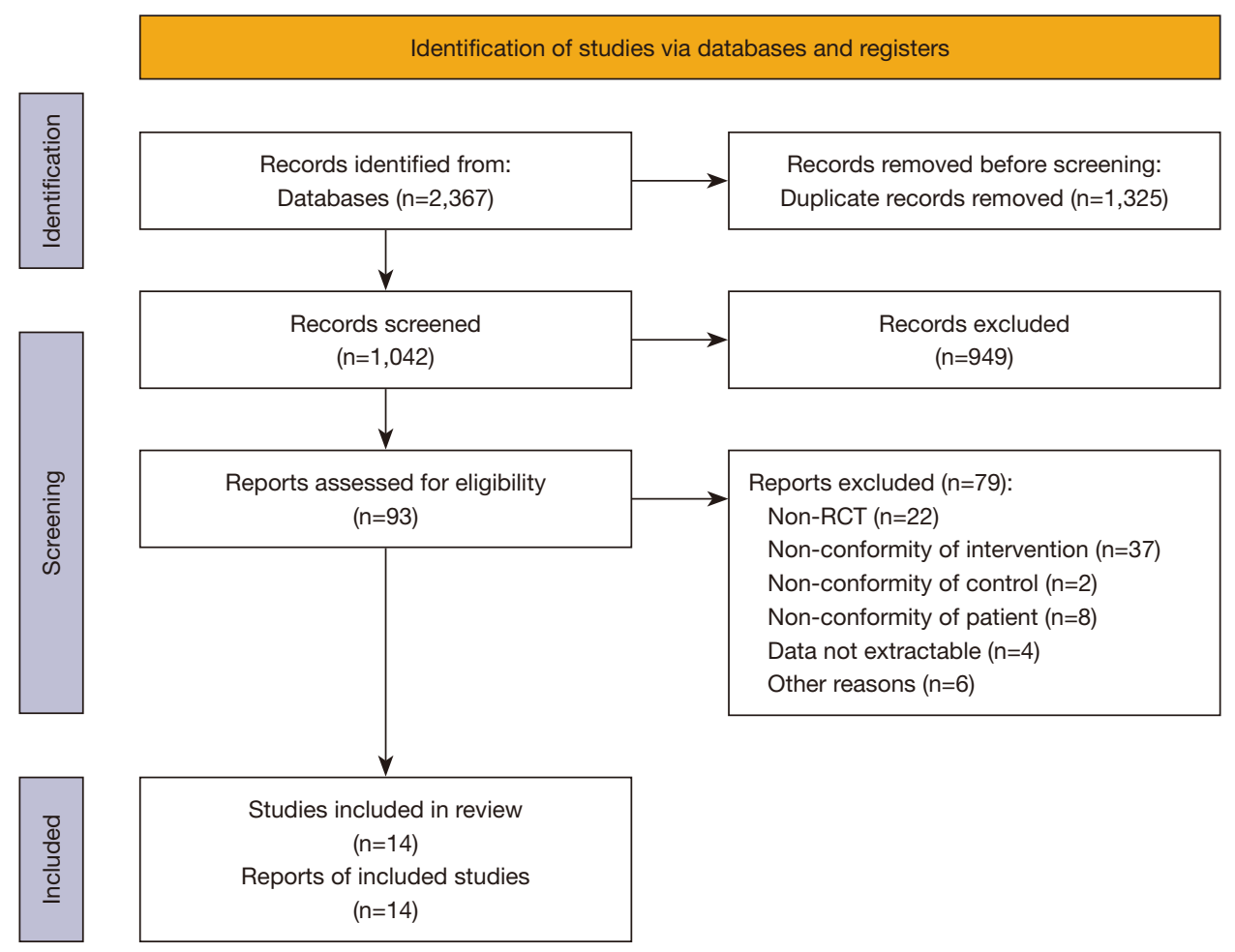

Figure 1 Flow diagram of literature search and trial selection. RCT, randomized controlled trial.

\section{Assessment of evidence quality}

The Grading of Recommendations Assessment Development and Evaluation (GRADE) system was used to rate the quality of evidence for each outcome. According to the GRADE guideline, the quality of evidence was divided into levels of high, moderate, low, and very low quality. The GRADEpro guideline development tool (GDT; https:// gradepro.org/) was applied to create the summary of evidence table (50-53).

\section{Subgroup analysis}

Subgroup analysis was performed based on the difference in interventions, which was categorized as moxibustion alone, or moxibustion combined with other different therapies.

\section{Assessment of outcome}

We assessed the outcomes of moxibustion for PSD by the score of HAMD reducing, effective rate and MESSS scale scores. Since several studies (54-56) had used the HAMD as an outcome, we used the score of HAMD reducing as primary outcome in our review.

\section{Results}

\section{Description of studies}

The study selection processes were conducted according to the PRISMA flowchart and are shown in Figure 1. A total of 2,367 articles were identified initially from the seven databases, and 1,042 studies remained after deduplication. After a preliminary screening, 949 irrelevant articles were removed. The remaining 93 articles were re-screened, among which 14 RCTs met the inclusion criteria and were included in this study.

The characteristics of the included trials are shown in Table 1. These 14 studies were all conducted in China, involving a total of 863 PSD patients. The sample size of included trials ranged from 32 to 120 . The duration of treatments ranged from 3 to 12 weeks, with an average of 6.57 weeks. The age range of participants ranged from 23 to 90 years. Only 1 trial used moxibustion alone and compared it to fluoxetine in the control arms (39), to explore the effects of moxibustion used alone. In the other 13 trials, the intervention group involved moxibustion combined with conventional therapies, such as fluoxetine $(35,37,40)$, acupuncture $(36,41,43)$, CHM $(31,34,44)$, psychology 
Table 1 Characteristics of the included trials

\begin{tabular}{|c|c|c|c|c|c|c|c|}
\hline Study ID & $\begin{array}{c}\text { Total/treatment/ } \\
\text { control }\end{array}$ & $\begin{array}{c}\text { Age range/mean } \pm S D \\
\text { (years) }\end{array}$ & Treatment & Control & Frequency & Duration & $\begin{array}{l}\text { Outcome } \\
\text { indicators }\end{array}$ \\
\hline Cai 2020 (31) & $88 / 44 / 44$ & $\begin{array}{l}\mathrm{T}: 23-49 / 32 \pm 4.52 \\
\mathrm{C}: 23-50 / 29 \pm 4.36\end{array}$ & Moxibustion + CHM & $\mathrm{CHM}$ & 1 time/d & 8 weeks & $\begin{array}{l}\text { (I) HAMD; } \\
\text { (II) MESSS; } \\
\text { (III) effective rate }\end{array}$ \\
\hline Deng 2014 (32) & $80 / 40 / 40$ & $\begin{array}{l}\text { T: } 63.60 \pm 7.80 \\
\text { C: } 64.55 \pm 8.60\end{array}$ & $\begin{array}{l}\text { Moxibustion + } \\
\text { psychotherapy }\end{array}$ & $\begin{array}{l}\text { Fluoxetine + } \\
\text { psychotherapy }\end{array}$ & 1 time $/ d$ & 4 weeks & $\begin{array}{l}\text { (I) HAMD; } \\
\text { (II) effective rate; } \\
\text { (III) MESSS }\end{array}$ \\
\hline Deng 2019 (33) & $64 / 32 / 32$ & $\begin{array}{c}\text { T: } 24-90 / 7 \pm 16.31 ; \\
\text { C: } 35-85 / 8.88 \pm 14.10\end{array}$ & $\begin{array}{l}\text { Moxibustion + } \\
\text { basic treatment + } \\
\text { psychotherapy }\end{array}$ & $\begin{array}{c}\text { Basic treatment + } \\
\text { psychotherapy }\end{array}$ & NR & 8 weeks & $\begin{array}{l}\text { (I) HAMD; } \\
\text { (II) effective rate }\end{array}$ \\
\hline Gan 2021 (34) & $82 / 41 / 41$ & $\begin{array}{l}\mathrm{T}: 52.20 \pm 4.51 \\
\mathrm{C}: 51.98 \pm 4.67\end{array}$ & Moxibustion + CHM & $\mathrm{CHM}$ & 1 time/d & 12 weeks & (I) HAMD \\
\hline Luo 2017 (36) & $64 / 32 / 32$ & $\begin{array}{l}\text { T: } 60.29 \pm 8.35 \\
\text { C: } 61.27 \pm 9.85\end{array}$ & $\begin{array}{l}\text { Moxibustion + } \\
\text { acupuncture }\end{array}$ & Acupuncture & 1 time/d & 4 weeks & $\begin{array}{l}\text { (I) HAMD; } \\
\text { (II) effective rate }\end{array}$ \\
\hline Miao 2018 (37) & $32 / 16 / 16$ & $\begin{array}{l}\text { T: } 40-79 / 4.97 \pm 9.45 ; \\
\text { C: } 39-78 / 4.13 \pm 9.26\end{array}$ & $\begin{array}{l}\text { Moxibustion + } \\
\text { fluoxetine }\end{array}$ & Fluoxetine & 1 time/d & 8 weeks & $\begin{array}{l}\text { (I) HAMD; } \\
\text { (II) effective rate }\end{array}$ \\
\hline Niu 2015 (38) & $120 / 60 / 60$ & $\begin{array}{c}\text { T: } 48-75 / 8.64 \pm 8.92 ; \\
\text { C: } 48-75 / 60.23 \pm 10.51\end{array}$ & $\begin{array}{l}\text { Moxibustion } \\
+ \text { fluoxetine + } \\
\text { acupuncture }\end{array}$ & $\begin{array}{l}\text { Fluoxetine + } \\
\text { acupuncture } \\
\text { treatment }\end{array}$ & 1 time/d & 6 weeks & (I) HAMD \\
\hline Shan 2017 (39) & $60 / 30 / 30$ & $\begin{array}{l}\text { T: } 44-64 / 5.45 \pm 3.16 ; \\
\text { C: } 46-65 / 6.49 \pm 3.19\end{array}$ & Moxibustion & Fluoxetine & 1 time $/ d$ & 8 weeks & $\begin{array}{l}\text { (I) HAMD; } \\
\text { (II) effective rate }\end{array}$ \\
\hline Zhai 2021 (43) & $48 / 24 / 24$ & $\begin{array}{l}\text { T: } 56.27 \pm 7.59 \\
\text { C: } 57.01 \pm 6.72\end{array}$ & $\begin{array}{l}\text { Moxibustion + } \\
\text { acupuncture }\end{array}$ & Acupuncture & 1 time/d & 6 weeks & (I) HAMD \\
\hline Zou 2014 (44) & $54 / 27 / 27$ & $\begin{array}{l}\text { T: } 61.43 \pm 9.62 ; \\
\text { C: } 59.36 \pm 10.23\end{array}$ & Moxibustion + CHM & $\mathrm{CHM}$ & 1 time $/ d$ & 3 weeks & (I) HAMD \\
\hline
\end{tabular}

T, treatment group; C, control group; CHM, Chinese herbal medicine; HAMD, Hamilton Depression Rating Scale; MESSS, Modified Edinburgh-Scandinavian Stroke Scale.

guidance $(32,33)$, and combination of acupuncture and fluoxetine (38).

\section{Quality assessment}

The judgment regarding each risk of bias item is shown in
Figure 2. A total of 10 trials reported the method of random sequence generation, among which $3(38,41,44)$ were high risk and 7 trials $(32,34-36,39,40,43)$ reported "randomly allocating", which was classified as low risk. For allocation concealment, 2 RCTs $(35,36)$ were assessed as low risk and $9(31,34,38-44)$ were high risk. Meanwhile, due to 


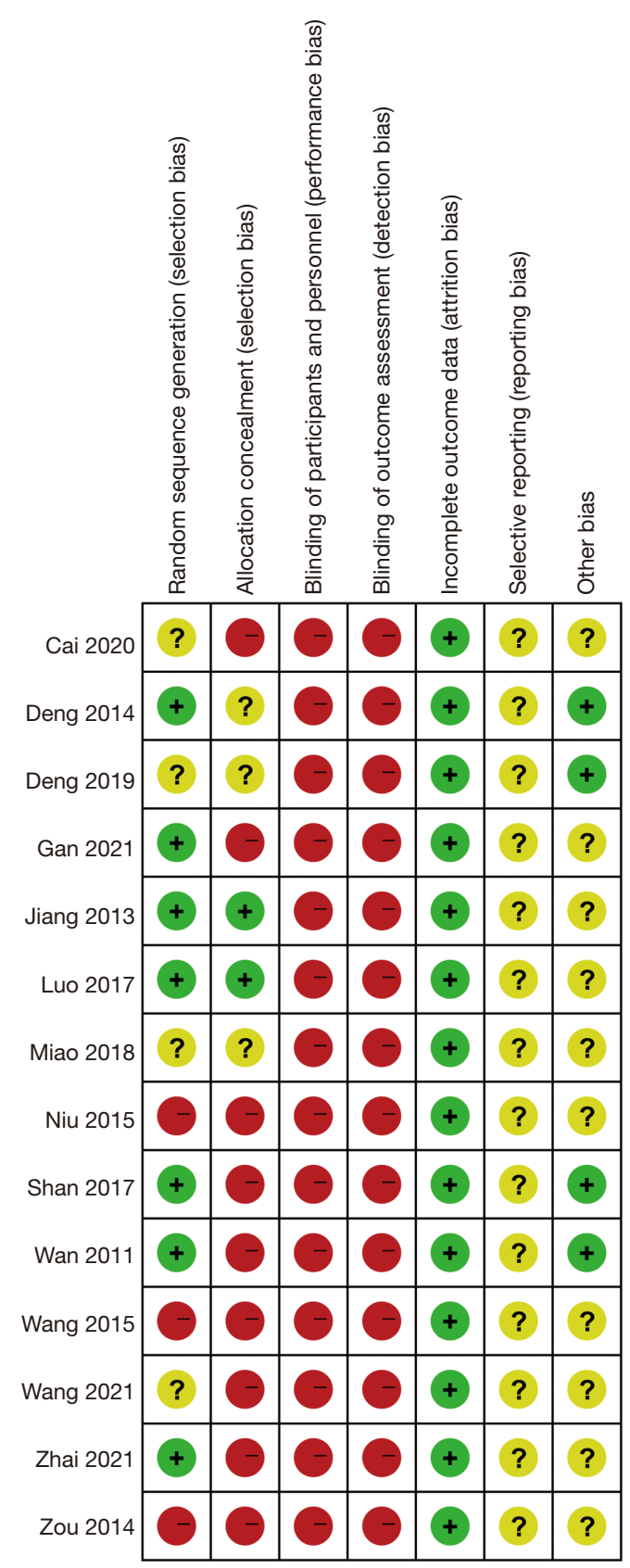

Figure 2 Risk of bias for included studies.

inability to implement blinding, all the bias risk of blinding were assessed as high risk. All the included trials provided complete outcome data, and without attrition bias. Selective reporting bias of all the trials was unclear due to their protocols being unavailable. The bias of the other 4 trials $(32,33,39,40)$ were low risk due to providing clear conflict of interest, and the other 10 trials $(31,34-38,41-44)$ were judged as "unclear".

\section{Outcomes}

\section{Primary outcomes HAMD}

The comparison of HAMD scale scores is shown in Figure 3. All studies, which included a total of 914 patients, reported HAMD scale scores. Due to significant heterogeneity, a random-effects model was used for statistical analysis. Results showed that when compared with the control group, the change in value of the treatment group was statistically significant $(\mathrm{SMD}=-1.17 ; 95 \% \mathrm{CI}:-1.55$ to $\left.-0.79 ; \mathrm{I}^{2}=85.5 \% ; \mathrm{P}<0.01\right)$.

Subgroup analysis was used according to the variation of different interventions. The result of each subgroup showed that compared with the other treatments, moxibustion combined with $\mathrm{CHM}$ ( $\mathrm{SMD}=-2.42 ; 95 \% \mathrm{CI}$ : -3.80 to $\left.-1.03 ; \mathrm{I}^{2}=93.6 \% ; \mathrm{P}<0.01\right)(31,34,44)$, fluoxetine $\left(\mathrm{SMD}=-1.08 ; 95 \% \mathrm{CI}:-1.69\right.$ to $\left.-0.47 ; \mathrm{I}^{2}=66.1 \% ; \mathrm{P}=0.05\right)$ $(35,37,42)$, acupuncture $(\mathrm{SMD}=-0.64 ; 95 \% \mathrm{CI}:-0.96$ to $\left.-0.31 ; \mathrm{I}^{2}=0.0 \% ; \mathrm{P}=0.99\right)(36,41,43)$, fluoxetine and acupuncture together (SMD $=-1.73 ; 95 \% \mathrm{CI}:-2.15$ to -1.31 ) (38), and moxibustion alone (SMD $=-0.92 ; 95 \%$ CI: -1.30 to $\left.-0.55 ; \mathrm{I}^{2}=0.0 \% ; \mathrm{P}=0.38\right)(39,40)$, respectively, had a statistically significant ability to decrease HAMD scores. However, there was no statistically significant difference between moxibustion plus psychology therapies group and conventional treatment group (SMD $=-0.46 ; 95 \%$ CI: -1.03 to $\left.0.11, \mathrm{I}^{2}=65.6 \%, \mathrm{P}=0.09\right)(32,33)$.

\section{Secondary outcomes Effective rate}

The comparison of effective rate is shown in Figure 4. A total of 10 studies (31-37,39-41), which included a cumulative 632 participants, reported the outcome of effective rate. Due to insignificant heterogeneity, the fixedeffects model was used for statistical analysis. The results showed that compared to the control group, the effective rate in the treatment group was better, and the difference was statistically significant $(\mathrm{RR}=1.22 ; 95 \% \mathrm{CI}: 1.13$ to 1.32 ; $\mathrm{I}^{2}=0.0 \% ; \mathrm{P}=0.56$ ).

Subgroup analysis indicated that CHM $(\mathrm{RR}=1.18$; 95\% CI: 1.04 to $\left.1.33 ; \mathrm{I}^{2}=66.9 \%, \mathrm{P}=0.08\right)(31,34)$, psychology ( $R R=1.28 ; 95 \% \mathrm{CI}: 1.06$ to $1.54 ; \mathrm{I}^{2}=0.0 \%$; $\mathrm{P}=0.48)(32,33)$, fluoxetine ( $\mathrm{RR}=1.32 ; 95 \% \mathrm{CI}: 1.06$ to $\left.1.66 ; \mathrm{I}^{2}=0.0 \% ; \mathrm{P}=0.84\right)(35,37)$, and acupuncture (RR $=1.21 ; 95 \%$ CI: 1.01 to $\left.1.44 ; \mathrm{I}^{2}=10.9 \% ; \mathrm{P}=0.29\right)(36,41)$, 


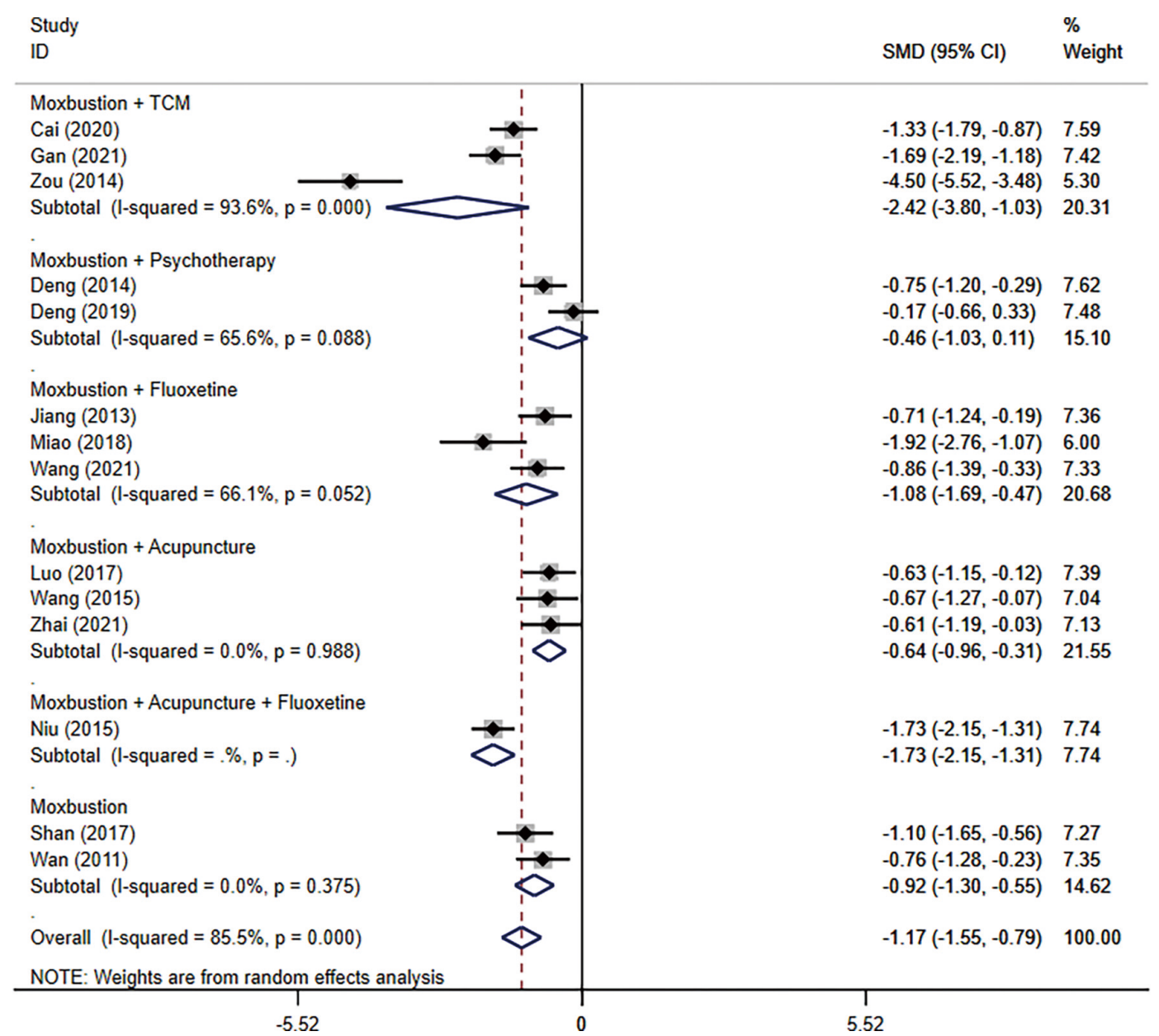

Figure 3 Comparison of the outcome of HAMD. HAMD, Hamilton Depression Rating Scale; SMD, standardized mean difference; CI, confidence interval; TCM, traditional Chinese medicine.

respectively, plus moxibustion have statistically significant impact on modifying effective rate. The other 2 trials used moxibustion alone compared to fluoxetine $(39,40)$ for which the difference in effective rate was not statistically significant ( $R R=1.18 ; 95 \%$ CI: 0.99 to $1.42 ; \mathrm{I}^{2}=0.0 \%$; $\mathrm{P}=0.68)$.

\section{MESSS}

The comparison of results from the MESSS scale is shown in Figure 5. A total of 2 studies $(32,40)$, which included a cumulative 140 patients, reported the outcome of the MESSS scale scores. Due to insignificant heterogeneity, the fixed-effects model was used for statistical analysis. Our results showed that compared with the control groups, the MESSS scale results were improved in the treatment group, and the difference was statistically significant $(\mathrm{SMD}=-0.72$; 95\% CI: -1.06 to $-0.38 ; \mathrm{I}^{2}=0.0 \% ; \mathrm{P}=0.80$ ).

\section{Publication bias}

Publication bias regarding the HAMD scale was assessed using funnel plots (Figure 6). The Begg's test and Egger's test of HAMD demonstrated that the $\mathrm{P}$ values were all greater than 0.05 (Begg's test, $\mathrm{P}=0.443$; Egger's test, $\mathrm{P}=0.097)$, which showed no significant symmetry, indicating no publication bias of the primary outcome.

\section{Summary of evidence}

The evidence quality of moxibustion for PSD is shown in Table 2. Generally, the quality was not high. The outcome of HAMD and MESSS had very low certainty, and the outcome of effective rate had low certainty. 


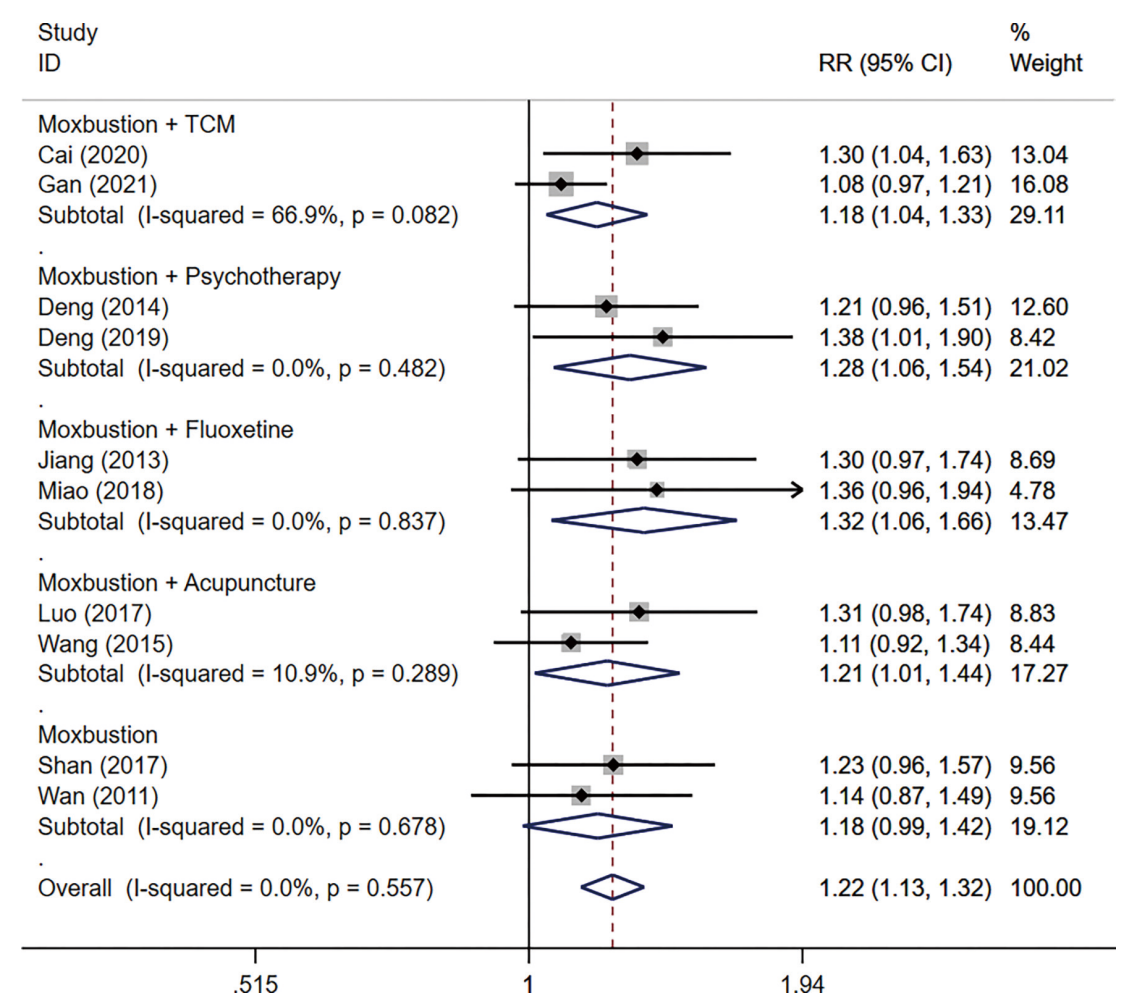

Figure 4 Comparison of effective rate. RR, risk ratio; CI, confidence interval; TCM, traditional Chinese medicine.

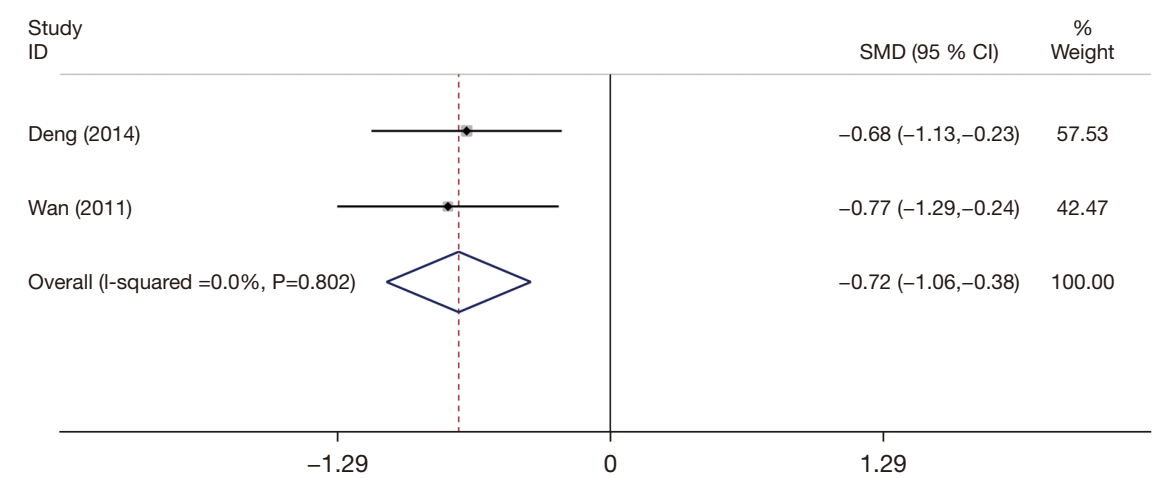

Figure 5 Comparison of MESSS scale. MESSS, Modified Edinburgh-Scandinavian Stroke Scale; SMD, standardized mean difference; CI, confidence interval.

\section{Discussion}

\section{Summary of main results}

A total of 14 RCTs were included and systematically evaluated the effectiveness and safety of moxibustion for PSD. Overall, on the basis of conventional treatment, adding moxibustion reduced the score of HAMD by
1.17 (0.79 to 1.55$)$ scores, effective rate, and MESSS. However, subgroup analysis showed that compared with conventional treatment, although the effect of moxibustion combined with psychotherapy on HAMD, and the effect of moxibustion alone on the effective effect had a favorable trend, the difference was not statistically significant. 


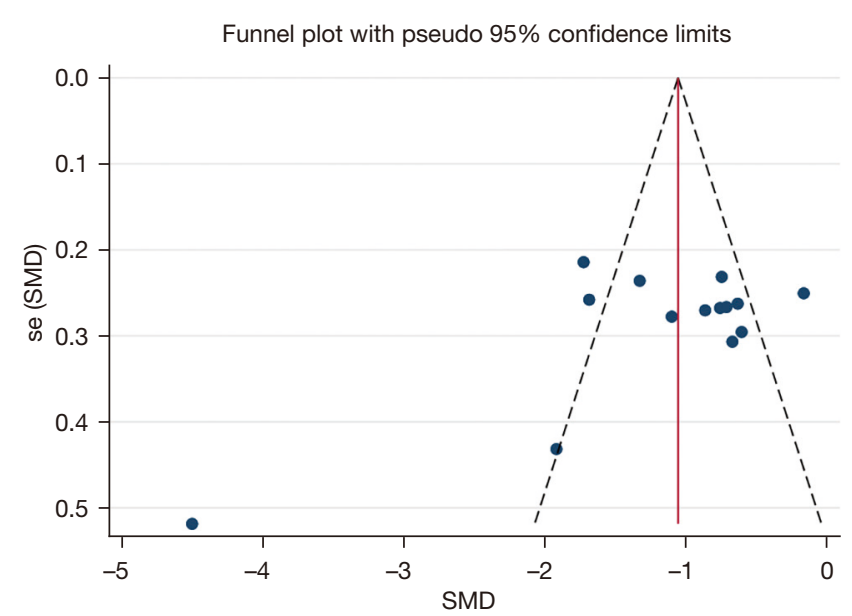

Figure 6 Publication bias regarding the scale of HAMD. HAMD, Hamilton Depression Rating Scale; SMD, standardized mean difference.

\section{Strengths and limitations of this systematic review}

The HAMD and MESSS scales are the currently recognized tools for evaluating the severity of PSD patients. Therefore, to strengthen the reliability of the efficacy of PSD patients, the above two outcomes and the effective rate were used to evaluate the efficacy of moxibustion on PSD patients. In addition, to explore the difference in the efficacy of moxibustion combined with other interventions for PSD patients, we also conducted a subgroup analysis according to the specific intervention methods.

There were some limitations in this study. Firstly, all the eligible trials were available from China, which may limit the application of the results. Secondly, there was a certain clinical heterogeneity in the interventions of the included studies. Although subgroup analysis of different interventions was performed, it made the sample size in the subgroup smaller and reduced the efficacy of the test. Thirdly, most of the included studies had flaws in methodological design, such as unclear allocation concealment or clinical trial registration. Last, all the included 14 articles were in Chinese. Our guess was that moxibustion therapy has not been popularized around the world, therefore, most of trials were conducted in China.

\section{Relation with previous works}

Previously, researchers systematically reviewed the efficacy of moxibustion in the treatment of PSD (57), but only 5 articles were included at that time, and meta-analysis was not conducted. This study finally included 14 studies on moxibustion treatment of PSD. As the interventions were not completely the same in the included studies, we divided the study into five subgroups according to the specific intervention methods and performed meta-analysis of the overall efficacy and the efficacy of the subgroups. Also, previous studies have shown that moxibustion works by promoting the absorption of Trp in the brain and transferring the metabolism of Trp to serotonin, which can increase the production of serotonin and exert an antidepressant effect (25). In addition, compared to Western drugs for PSD, the advantages of traditional Chinese medicine (TCM) were safety and low side effects. Meanwhile, the external treatment of Chinese medicine had less damage to the gastrointestinal tract and little irritation to the liver and kidney. Meanwhile, the operation was simple and easy to learn.

\section{Implications for further studies}

Further research should be aimed at evaluating the curative effect of moxibustion, such as using moxibustion alone versus fluoxetine alone. In addition, it is recommended to use the HAMD scale as the main outcome evaluating the efficacy of PSD patients. At the same time, the safety of moxibustion needs to be evaluated and analyzed in detail.

\section{Conclusions}

This systematic review and meta-analysis provide a detailed summary of the efficacy of moxibustion in treating patients with PSD. Based on 14 trials with a certain content of methodological quality defects, moxibustion seemed to be safe and effective for reducing the HAMD scale score, MESSS scale score, and improving the effective rate in PSD patients. However, due to the limitations around the quality of evidence, we suggest a large scale multi-centered RCT 


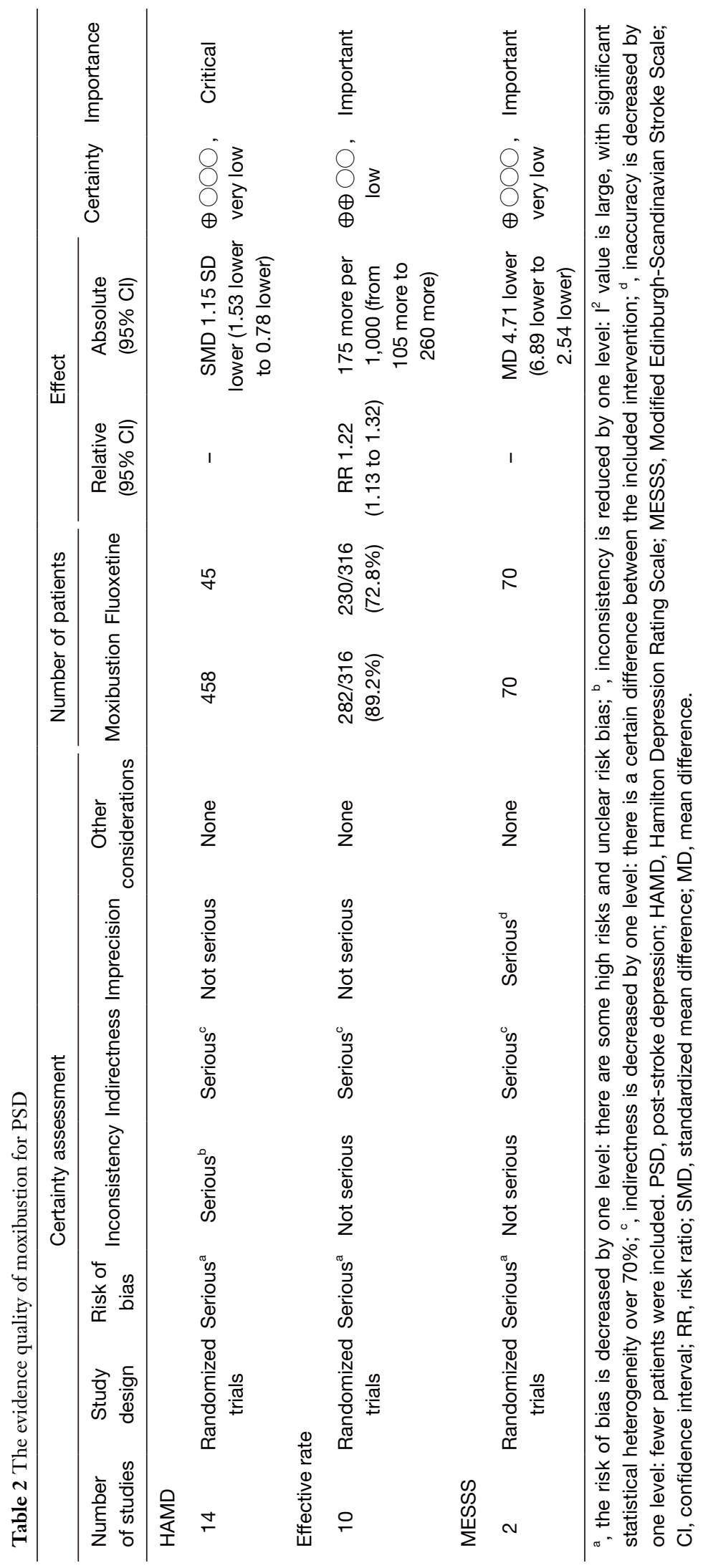


trial for moxibustion use as a PSD treatment be conducted in future.

\section{Acknowledgments}

Funding: This study was supported by National Key R\&D Program of China (No. 2019YFC1711901), National Key R\&D Program of China (No. 2019YFC1711903), the National Natural Science Foundation of China (No. 81874503).

\section{Footnote}

Reporting Checklist: The authors have completed the PRISMA reporting checklist. Available at https://apm. amegroups.com/article/view/10.21037/apm-21-3421/rc

Conflicts of Interest: All authors have completed the ICMJE uniform disclosure form (available at https://apm. amegroups.com/article/view/10.21037/apm-21-3421/coif). The authors have no conflicts of interest to declare.

Ethical Statement: The authors are accountable for all aspects of the work in ensuring that questions related to the accuracy or integrity of any part of the work are appropriately investigated and resolved.

Open Access Statement: This is an Open Access article distributed in accordance with the Creative Commons Attribution-NonCommercial-NoDerivs 4.0 International License (CC BY-NC-ND 4.0), which permits the noncommercial replication and distribution of the article with the strict proviso that no changes or edits are made and the original work is properly cited (including links to both the formal publication through the relevant DOI and the license). See: https://creativecommons.org/licenses/by-nc-nd/4.0/.

\section{References}

1. Hadidi NN, Huna Wagner RL, Lindquist R. Nonpharmacological Treatments for Post-Stroke Depression: An Integrative Review of the Literature. Res Gerontol Nurs 2017;10:182-95.

2. Paolucci S. Advances in antidepressants for treating post-stroke depression. Expert Opin Pharmacother 2017;18:1011-7.

3. Espárrago Llorca G, Castilla-Guerra L, Fernández Moreno MC, et al. Post-stroke depression: an update.
Neurologia 2015;30:23-31.

4. Matsuzaki S, Hashimoto M, Yuki S, et al. The relationship between post-stroke depression and physical recovery. J Affect Disord 2015;176:56-60.

5. Vojtikiv-Samoilovska D, Arsovska A. Prevalence and Predictors of Depression after Stroke - Results from a Prospective Study. Open Access Maced J Med Sci 2018;6:824-8.

6. Zhou X, Liu Z, Zhang $\mathrm{W}$, et al. Resilience is associated with post-stoke depression in Chinese stroke survivors: A longitudinal study. J Affect Disord 2020;273:402-9. Erratum in: J Affect Disord 2020;274:1232.

7. Ellis C, Zhao Y, Egede LE. Depression and increased risk of death in adults with stroke. J Psychosom Res 2010;68:545-51.

8. Guiraud V, Gallarda T, Calvet D, et al. Depression predictors within six months of ischemic stroke: The DEPRESS Study. Int J Stroke 2016;11:519-25.

9. Han B, Lyu Y, Sun H, et al. Low serum levels of vitamin $\mathrm{D}$ are associated with post-stroke depression. Eur J Neurol 2015;22:1269-74.

10. Ezema CI, Akusoba PC, Nweke MC, et al. Influence of Post-Stroke Depression on Functional Independence in Activities of Daily Living. Ethiop J Health Sci 2019;29:841-6.

11. Deng L, Sun X, Qiu S, et al. Interventions for management of post-stroke depression: A Bayesian network meta-analysis of 23 randomized controlled trials. Sci Rep 2017;7:16466.

12. Villa RF, Ferrari F, Moretti A. Post-stroke depression: Mechanisms and pharmacological treatment. Pharmacol Ther 2018;184:131-44.

13. Nabavi SF, Dean OM, Turner A, et al. Oxidative stress and post-stroke depression: possible therapeutic role of polyphenols? Curr Med Chem 2015;22:343-51.

14. Kawada T. Post-stroke depression: Risk assessment. J Neurol Sci 2018;387:228.

15. Lim MY, Huang J, Zhao B. Standardisation of moxibustion: challenges and future development. Acupunct Med 2015;33:142-7.

16. Cheng CW, Fu SF, Zhou QH, et al. Extending the CONSORT Statement to moxibustion. J Integr Med 2013;11:54-63.

17. Zhang HW, Lin ZX, Cheung F, et al. Moxibustion for alleviating side effects of chemotherapy or radiotherapy in people with cancer. Cochrane Database Syst Rev 2018;11:CD010559.

18. Guo MH, Zhao L, Wu F, et al. CO2 Laser Moxibustion 
for Knee Osteoarthritis: Study Protocol for A Multicenter, Double-blind, Randomized Controlled Trial. Chin J Integr Med 2020;26:568-76.

19. Li BR, Shao SY, Yuan L, et al. Effects of mild moxibustion on intestinal microbiome and NLRP3 inflammasome in rats with 5-fluorouracil-induced intestinal mucositis. J Integr Med 2021;19:144-57.

20. Huang XB, Xie DY, Qiu Q, et al. 42 cases of coronavirus disease 2019 of the ordinary type with the adjuvant treatment of heat-sensitive moxibustion 42. World J Acupunct Moxibustion 2020;30:163-6.

21. Park JW, Lee BH, Lee H. Moxibustion in the management of irritable bowel syndrome: systematic review and metaanalysis. BMC Complement Altern Med 2013;13:247.

22. Lee S, Jerng UM, Liu Y, et al. The effectiveness and safety of moxibustion for treating cancer-related fatigue: a systematic review and meta-analyses. Support Care Cancer 2014;22:1429-40.

23. Kim SY, Chae Y, Lee SM, et al. The effectiveness of moxibustion: an overview during 10 years. Evid Based Complement Alternat Med 2011;2011:306515.

24. Xu HF, Zhao BX. Mechanism of moxibustion therapy. Shanghai Journal of Acupuncture and Moxibustion 2012;31:6-9.

25. Li H, Sang L, Xia X, et al. Therapeutic Duration and Extent Affect the Effect of Moxibustion on DepressionLike Behaviour in Rats via Regulating the Brain Tryptophan Transport and Metabolism. Evid Based Complement Alternat Med 2019;2019:7592124.

26. Lin YF, Zhu JF, Chen YD, et al. Effect of ginger-separated moxibustion on fatigue, sleep quality and depression in patients with chronic fatigue syndrome: a randomized controlled trial. Zhongguo Zhen Jiu 2020;40:816-20.

27. Suzuki S, Tobe C. Effect of Acupressure, Acupuncture and Moxibustion in Women With Pregnancy-Related Anxiety and Previous Depression: A Preliminary Study. J Clin Med Res 2017;9:525-7.

28. Hung CY, Wu XY, Chung VC, et al. Overview of systematic reviews with meta-analyses on acupuncture in post-stroke cognitive impairment and depression management. Integr Med Res 2019;8:145-59.

29. Ren Y, Zhu C, Wu J, et al. Comparison between herbal medicine and fluoxetine for depression: a systematic review of randomized controlled trials. Complement Ther Med 2015;23:674-84.

30. Park H, Lee IS, Lee H, et al. Bibliometric Analysis of Moxibustion Research Trends over the Past 20 Years. J Clin Med 2020;9:1254.
31. Cai BW, Hao YJ, Dong YF, et al. The efficacy of moxibustion at Baihui acupoint combined with selfdeveloped traditional Chinese medicine prescriptions for post-cerebral infarction depression. HealthmustReadmagazine 2020;(8):178-9.

32. Deng YL, Tu CY, Liu Q, et al. Clinical observation on 40 cases of post-stroke depression and liver-qi stagnation syndrome treated by mild moxibustion. Nei Mongol Journal of Traditional Chinese Medicine 2014;33:94-5.

33. Deng KS, Liu J, Huang JH, et al. Clinical observation of thermal moxibustion combined with modified Morita therapy in the treatment of post-stroke depression. Jiangxi Journal of Traditional Chinese Medicine 2019;50:50-2.

34. Gan XS. Clinical effects of moxibustion at the Baihui point plus the Yujin decoction on depression after cerebral infarction. Clinical Journal of Chinese Medicine 2021;13:74-6.

35. Jiang LH. Clinical study of moxibustion combined with Prozac in the treatment of post-stroke depression. Nanjing: Nanjing University of Traditional Chinese Medicine, 2013.

36. Luo FF. The effect of acupuncture and moxibustion on the subjective emotions and neurotransmitters of patients with deficient depression after cerebral infarction. Fuzhou: Fujian University of Traditional Chinese Medicine, 2017.

37. Miao FG. Clinical observation on 32 cases of post-cerebral infarction depression treated with fluoxetine hydrochloride combined with moxibustion. Psychological Doctor 2018;24:101.

38. Niu YL, Liu CM, Wang XD, et al. Effect of Acupuncture Combined with Moxibustion on Heart Rate Variability in Patients with Post-stroke Depression. Chinese Journal of Rehabilitation Theory and Practice 2015;21:196-8.

39. Shan N. Curative Observation of Liushen Point Moxibustion Combined with Emotional Nursing Treatment for Treating Depression after Stroke. Journal of Sichuan Traditional Chinese Medicine 2017;35:180-2.

40. Wan GQ, Ma HM, Zhou GX, et al. The Efficacy of Remin Moxibustion on Post Stroke Depression. Journal of Clinical Acupuncture and Moxibustion 2011;27:9-11.

41. Wang YL, Yao L. Efficacy of Baixiao moxibustion in treating depression after stroke. Shanghai Journal of Acupuncture and Moxibustion 2015;34:595-6.

42. Wang H, Yang BD. Clinical Study on Sandwiched Moxibustion at Shenque (RN8) Combined with Traditional Chinese Medicine Emotional Therapy in the Treatment of Post-stroke Depression and Insomnia. Guangming Journal 
of Chinese Medicine 2021;36:2578-81.

43. Zhai XH, Li L, Yu M, et al. The effect of moxibustion at Zusanli point combined with emotional nursing on patients with post-stroke depression. Modern Medicine Journal of China 2021;23:88-90.

44. Zou SY, Liu H. Observation of Curative Effects of Traditional Chinese Medicine Dialectical Nursing with Moxa-Wool Moxibustion on Post-Stroke of Both Heart and Spleen Deficiency. Journal of Liaoning University of Traditional Chinese Medicine 2014;16:196-8.

45. Page MJ, McKenzie JE, Bossuyt PM, et al. The PRISMA 2020 statement: an updated guideline for reporting systematic reviews. BMJ 2021;372:n71.

46. Higgins JP, Altman DG, Gøtzsche PC, et al. The Cochrane Collaboration's tool for assessing risk of bias in randomised trials. BMJ 2011;343:d5928.

47. Cai W, Mueller C, Li YJ, et al. Post stroke depression and risk of stroke recurrence and mortality: A systematic review and meta-analysis. Ageing Res Rev 2019;50:102-9.

48. Furlan AD, Pennick V, Bombardier C, et al. 2009 updated method guidelines for systematic reviews in the Cochrane Back Review Group. Spine (Phila Pa 1976) 2009;34:1929-41.

49. Higgins JP, Thompson SG. Quantifying heterogeneity in a meta-analysis. Stat Med 2002;21:1539-58.

50. Balshem H, Helfand M, Schünemann HJ, et al. GRADE guidelines: 3 . Rating the quality of evidence. J Clin

Cite this article as: Guo SQ, Zhao GZ, Li ST, Yao Q, Han L, Li B, Wang H, Liu YJ, Zhao BX. Moxibustion for treating patients with post-stroke depression: a systematic review and meta-analysis. Ann Palliat Med 2022;11(1):85-97. doi: 10.21037/ apm-21-3421
Epidemiol 2011;64:401-6.

51. Guyatt GH, Oxman AD, Vist G, et al. GRADE guidelines: 4. Rating the quality of evidence--study limitations (risk of bias). J Clin Epidemiol 2011;64:407-15.

52. Guyatt GH, Oxman AD, Montori V, et al. GRADE guidelines: 5 . Rating the quality of evidence--publication bias. J Clin Epidemiol 2011;64:1277-82.

53. Guyatt GH, Oxman AD, Kunz R, et al. GRADE guidelines: 7. Rating the quality of evidence--inconsistency. J Clin Epidemiol 2011;64:1294-302.

54. Sarfo FS, Agbenorku M, Adamu S, et al. The dynamics of Poststroke depression among Ghanaians. J Neurol Sci 2019;405:116410.

55. Turner-Stokes L, Hassan N. Depression after stroke: a review of the evidence base to inform the development of an integrated care pathway. Part 1: Diagnosis, frequency and impact. Clin Rehabil 2002;16:231-47.

56. Mahadevan S, Chan MF, Moghadas M, et al. Post-Stroke Psychiatric and Cognitive Symptoms in West Asia, South Asia and Africa: A Systematic Review and Meta-Analysis. J Clin Med 2021;10:3655.

57. Lv XL, Sun ZG, Zhang QH, et al. Clinical systematic review of moxibustion for stroke and depression. Shanghai Journal of Acupuncture and Moxibustion 2013;32:954-6.

(English Language Editor: J. Jones) 


\section{Supplementary}

Table S1 Search strategy of PubMed

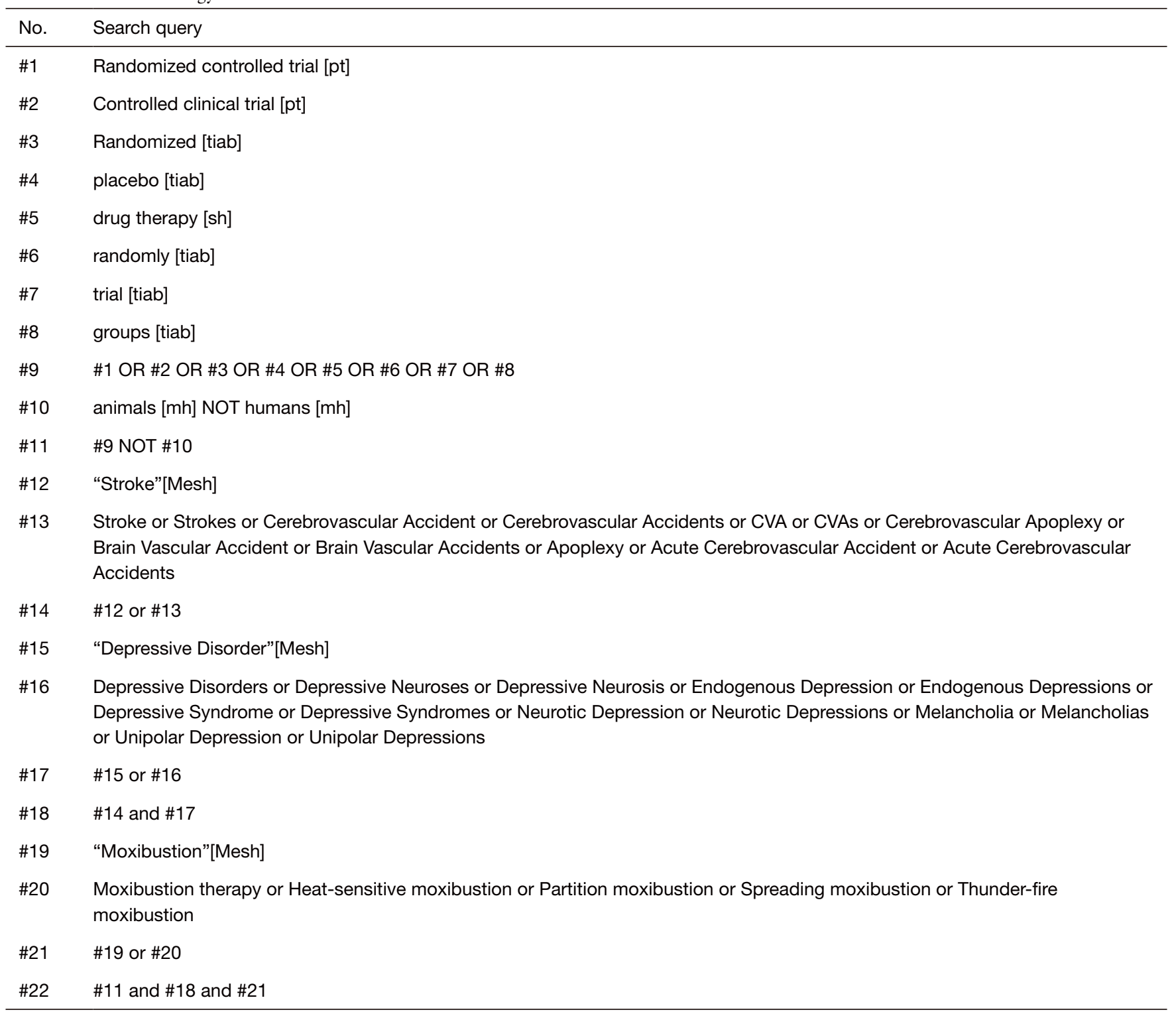

CVA, cerebrovascular accident. 